\title{
Experiences of taking neuroleptic medication and impacts on symptoms, sense of self and agency: a systematic review and thematic synthesis of qualitative data
}

\author{
Jemima Thompson ${ }^{1,2} \cdot$ Jacki L. Stansfeld ${ }^{2,3} \cdot$ Ruth E. Cooper $^{4} \cdot$ Nicola Morant $^{3} \cdot$ Nadia E. Crellin ${ }^{2,3}$. \\ Joanna Moncrieff ${ }^{2,3}$ (D)
}

Received: 21 May 2019 / Accepted: 13 December 2019 / Published online: 24 December 2019

(c) The Author(s) 2019

\begin{abstract}
Purpose Neuroleptic (antipsychotic) drugs reduce psychotic symptoms, but how they achieve these effects and how the drugs' effects are experienced by people who take them are less well understood. The present study describes a synthesis of qualitative data about mental and behavioural alterations associated with taking neuroleptics and how these interact with symptoms of psychosis and people's sense of self and agency.

Methods Nine databases were searched to identify qualitative literature concerning experiences of taking neuroleptic medication. A thematic synthesis was conducted.

Results Neuroleptics were commonly experienced as producing a distinctive state of lethargy, cognitive slowing, emotional blunting and reduced motivation, which impaired functioning but also had beneficial effects on symptoms of psychosis and some other symptoms (e.g. insomnia). For some people, symptom reduction helped restore a sense of normality and autonomy, but others experienced a loss of important aspects of their personality. Across studies, many people adopted a passive stance towards long-term medication, expressing a sense of resignation, endurance or loss of autonomy.

Conclusions Neuroleptic drugs modify cognition, emotions and motivation. These effects may be associated with reducing the intensity and impact of symptoms, but also affect people's sense of self and agency. Understanding how the effects of neuroleptics are experienced by those who take them is important in developing a more collaborative approach to drug treatment in psychosis and schizophrenia.
\end{abstract}

Keywords Antipsychotics $\cdot$ Neuroleptics $\cdot$ Psychosis $\cdot$ Schizophrenia $\cdot$ Qualitative research

Joanna Moncrieff

j.moncrieff@ucl.ac.uk

1 Research Department of Medical Education (RDME), Royal Free Hospital, University College London, London, UK

2 Research and Development Department, Goodmayes Hospital, North East London NHS Foundation Trust, Essex, UK

3 Division of Psychiatry, University College London, London, UK

4 Unit for Social and Community Psychiatry, Newham Centre for Mental Health, Queen Mary University of London, London, UK

\section{Introduction}

Neuroleptic medication (also known as 'antipsychotic' medication) is the primary treatment for people with a diagnosis of schizophrenia or other psychotic disorders [1,2]. There is evidence that it reduces acute psychotic symptoms and risk of relapse [3]. However, neuroleptics have many adverse effects and recent accounts suggest they may be overused [4-6]. The action of neuroleptics is thought to be mediated through their effects on neurotransmitters, but the manner in which they modify symptoms remains uncertain. Early pioneers of neuroleptic treatment suggested that the ability of neuroleptics to reduce the intensity of emotional responses and motivation was relevant to their neuroleptic effects [7, 8], and this idea has been reiterated more recently [8-10]. These effects are also likely to impact on other areas of people's experience, such as their sense of self and agency, 
including their sense of choice and power over treatment decisions. Indeed, research has shown that people's sense of self and agency are affected by the use of other mindmodifying medicines, such as anti-depressants $[11,12]$.

Several qualitative studies have been conducted that describe the experiences of taking neuroleptics [13]. The rich nature of qualitative data means these studies can highlight the complex alterations to conscious experience, mental functions and behaviour that neuroleptics produce, arguably more successfully than quantitative approaches (e.g. use of side effect scales). It can also clarify how such effects interact with symptoms of psychosis, and how they impact on people's sense of self and agency. The current study is a systematic review of the literature that is aimed to explore these issues using qualitative methods. Specifically, our research addresses the following questions:

1. What does qualitative research indicate about the mental and behavioural alterations produced by neuroleptic drugs and how do these impact on symptoms?

2. How do neuroleptics affect people's sense of self and agency?

The first question aims to establish the particular experiences induced by neuroleptic drugs, and how these might interact with symptoms. In relation to the second question, we define the sense of self as an individual's view of the distinctive features of their own character [14], and agency can be summarised briefly as having the ability to influence what happens in one's life [15].

\section{Methods}

The systematic review was conducted in accordance with PRISMA (Preferred Reporting Items for Systematic Reviews) guidelines [16] (protocol available at: https:// www.crd.york.ac.uk/PROSPERO/display_record.php?Recor $\mathrm{dID}=55646$. Registration number; 55646).

\section{Eligibility criteria}

Studies were included if they reported qualitative data about the experiences and views of people taking neuroleptic medication for a mental health condition and were written in English. Unpublished data were included and no date of publication range was specified. Studies only describing the views of clinicians or carers were not included.

\section{Search}

Repeated searches of the following electronic databases were conducted from inception of the project in 2017 until
7 March 2019: Ovid MEDLINE, EMBASE, PsycINFO, PsycARTICLES, the Cochrane Library, CINAHL, Scopus and AMED. OpenGrey was also searched for unpublished literature. Hand searching of citations was also conducted. The following search terms were used: ("neuroleptic*" OR "atypical antipsychotic*" OR "neuroleptic*" OR "major tranquiliser*" OR "psychotropic*" OR "depot injection*" OR "psychiatric medication*") AND ("attitude*" OR "experience*" OR "subjective*" OR "opinion*" OR "side-effect*" OR "complian*" OR "adheren*" OR "satisfaction*" OR "perception*" OR "understanding*" OR "interpretation*” OR "view*" OR "tolerability*” OR "perspective*” OR “insight*” OR "quality of life*” or "personal account*").

\section{Study selection}

All titles and abstracts identified in the searches were screened to see whether they fulfilled eligibility criteria, and the full papers selected through this process were assessed by two reviewers (JT and JS). Queries about inclusion were resolved through consultation with two other reviewers (JM, $\mathrm{RC})$.

\section{Quality review}

Study quality was assessed by two reviewers (JT and JS) using the Critical Appraisal Skills Programme (CASP) qualitative checklist [17]. The CASP was chosen since it is recommended by the Cochrane Collaboration [18] and is widely used in qualitative synthesis. Before commencing independent quality assessments, reviewers assessed the same five papers, with high interrater reliability (96\%).

In line with recommendations for qualitative research synthesis, we did not set quality criteria for inclusion [19, 20].

\section{Data extraction, analysis and interpretation}

All parts of the results and discussion sections of included papers that described or analysed study participants' experiences of taking neuroleptics were extracted and imported into the qualitative analysis software NVivo 11 . We used thematic synthesis [20] to analyse this material (referred to in the process described below as 'data'). Thematic synthesis is an established method that uses the basic principles and practices of thematic analysis [21] to draw together key themes from across studies, and in so doing develop further interpretations or new analytic insight [20]. Similar to thematic analysis, thematic synthesis offers a standardised but flexible approach that can be used to integrate relatively large numbers of qualitative studies and is recommended for topics in mental health [19]. 
Our analysis proceeded as follows: Initially, the first reviewer (JT) and last reviewer (JM) read all the papers in detail to obtain an overview of the issues covered. Then the first reviewer coded the data from each of the papers line by line, with the second reviewer (JS) coding a sample of papers. The data were initially coded into descriptive themes, which directly described the findings of each of the included papers. Themes and sub-themes were collated in tables and a hierarchical descriptive tree, to compare and match themes across articles. This process went through several iterations with input from the whole research team. Descriptive themes were then grouped into analytic themes which were refined collaboratively through a further process of iteration. This step involves "going beyond the descriptive synthesis to produce a more conceptual line of argument" [19] (P 7). As with thematic analysis, we endeavoured to enhance validity through reflexive and collaborative working, in which we discussed and questioned theoretical and personal positions held by team members [22]. The detailed coding process, iterative consideration of descriptive and analytical themes and constant input of the whole research team ensured that there was strong consensus across the research team about the conceptualisation of themes and their relationships to the data.

\section{Results}

The search strategy identified 11,292 references. Of these, 103 full text articles were assessed for eligibility and 69 were excluded (see Fig. 1 for reasons for exclusion). A total of 35 studies were included in the review, including 34 published studies and 1 unpublished doctoral thesis.

\section{Study characteristics}

Of the 35 included studies, participants were recruited from a variety of settings across 11 different countries, including inpatient facilities, community-based services, first episode psychosis services, general youth services and one was conducted in a prison. Twenty-one studies were restricted to people with a diagnosis of schizophrenia, a psychotic disorder or bipolar disorder. One study included people with borderline personality disorder and eight did not specify diagnoses. Data were mainly collected via face to face interviews $(N=21)$ with other studies using a mixture of focus groups, interviews and diary entries $(N=8)$, questionnaires/surveys $(N=3)$ and data from Internet fora $(N=1)$ (see Table 1). One study explored the effects of clozapine specifically [23], and
Fig. 1 Preferred Reporting Items For Systematic Reviews and Meta-Analyses (PRISMA) flow diagram

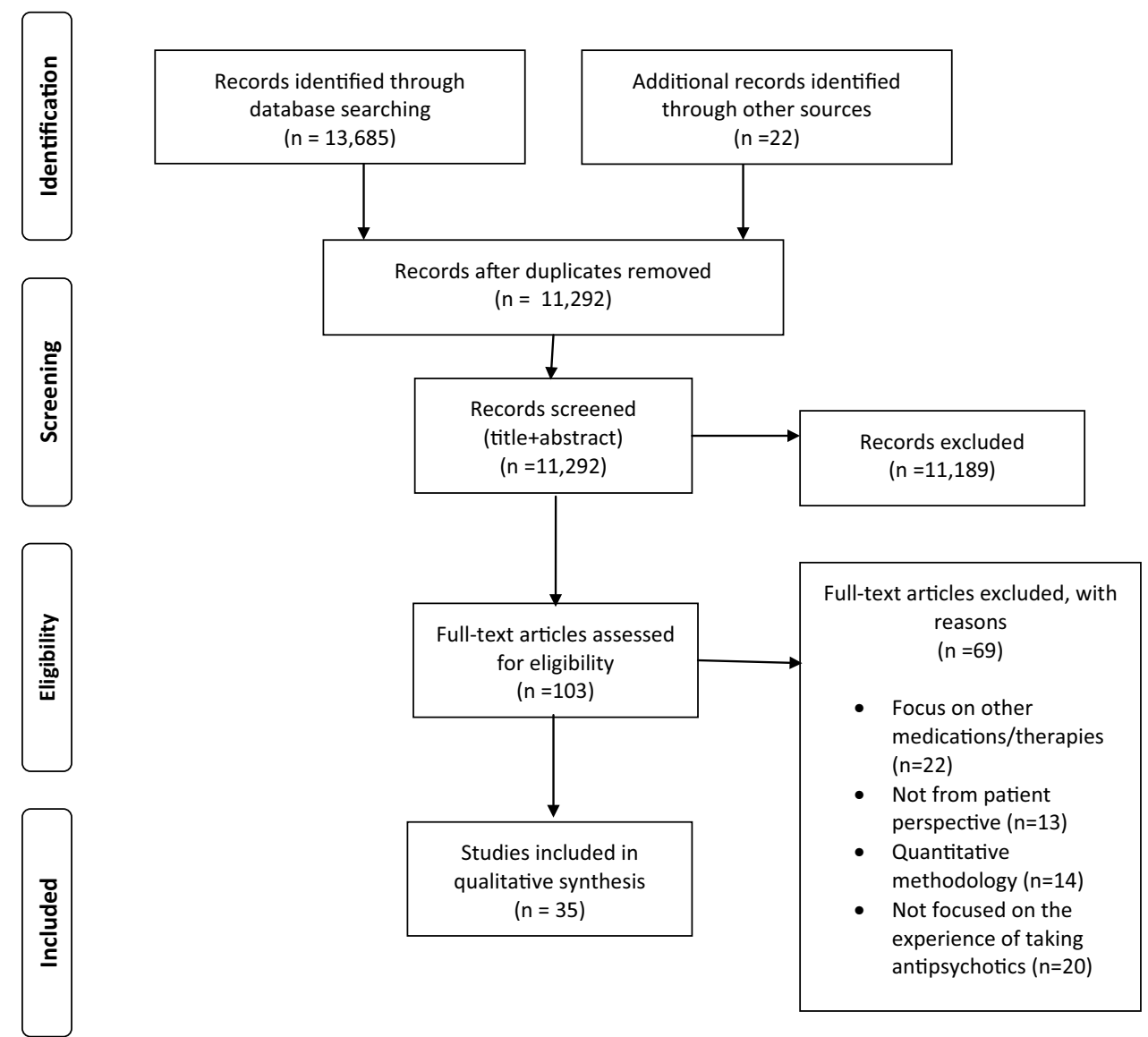




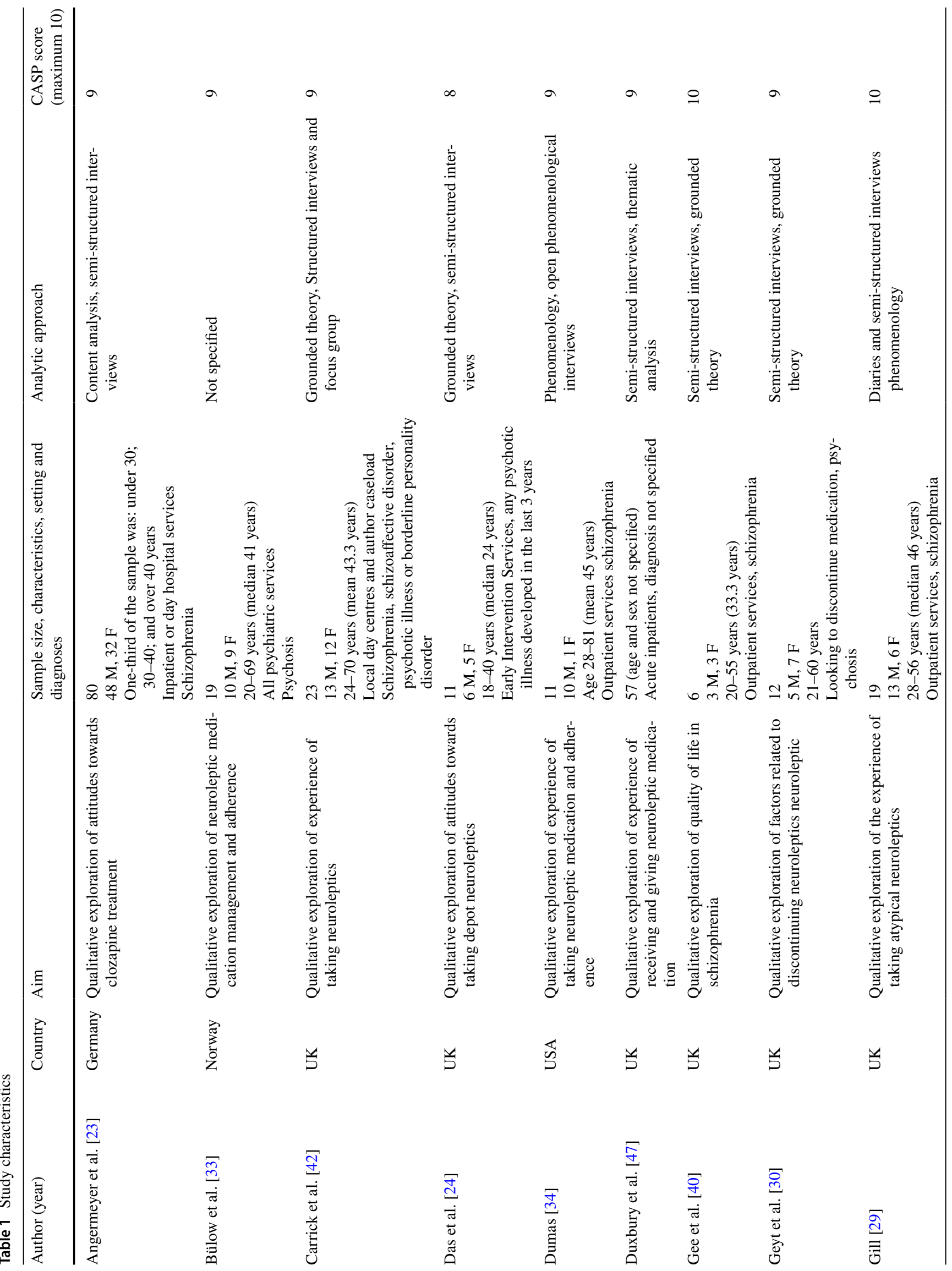




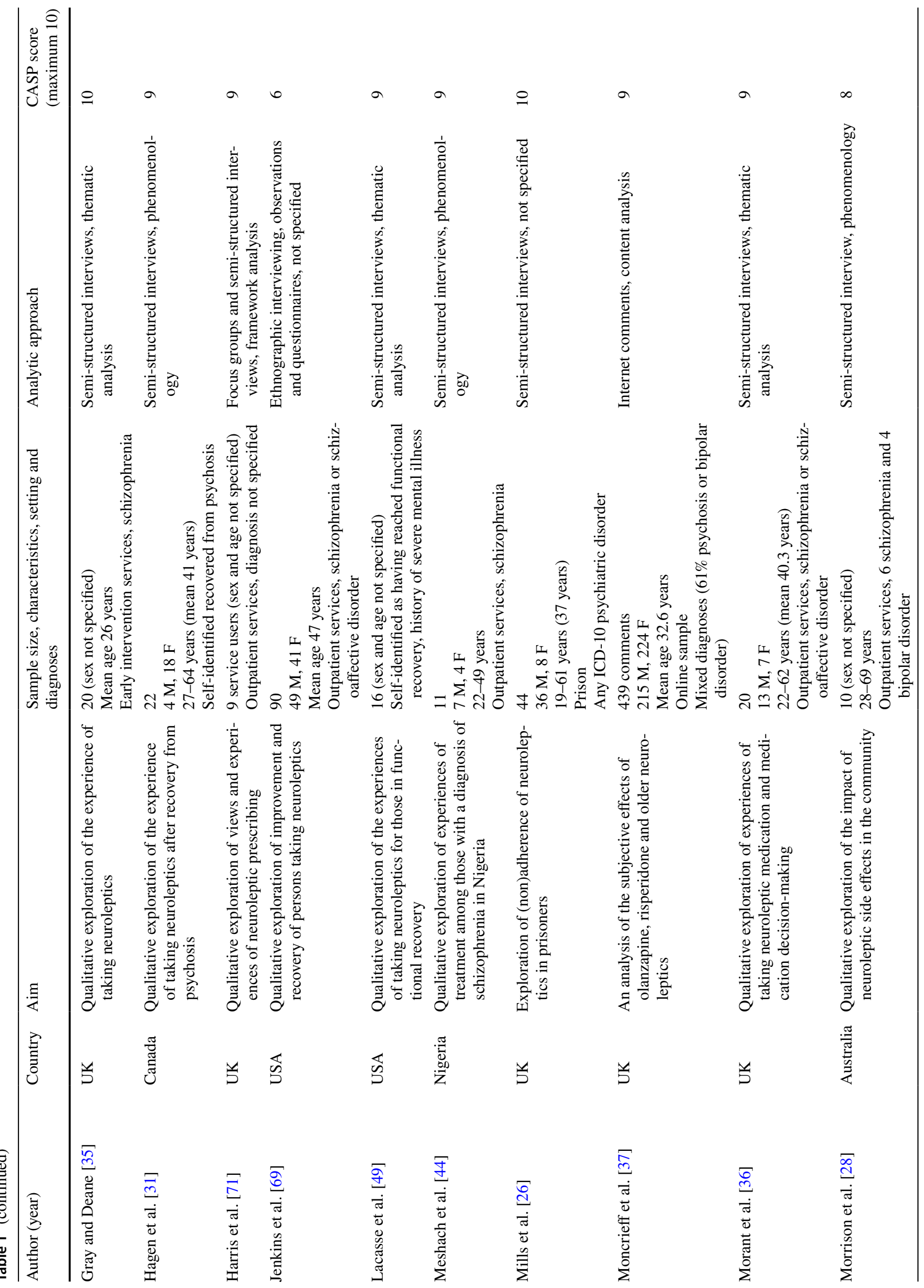




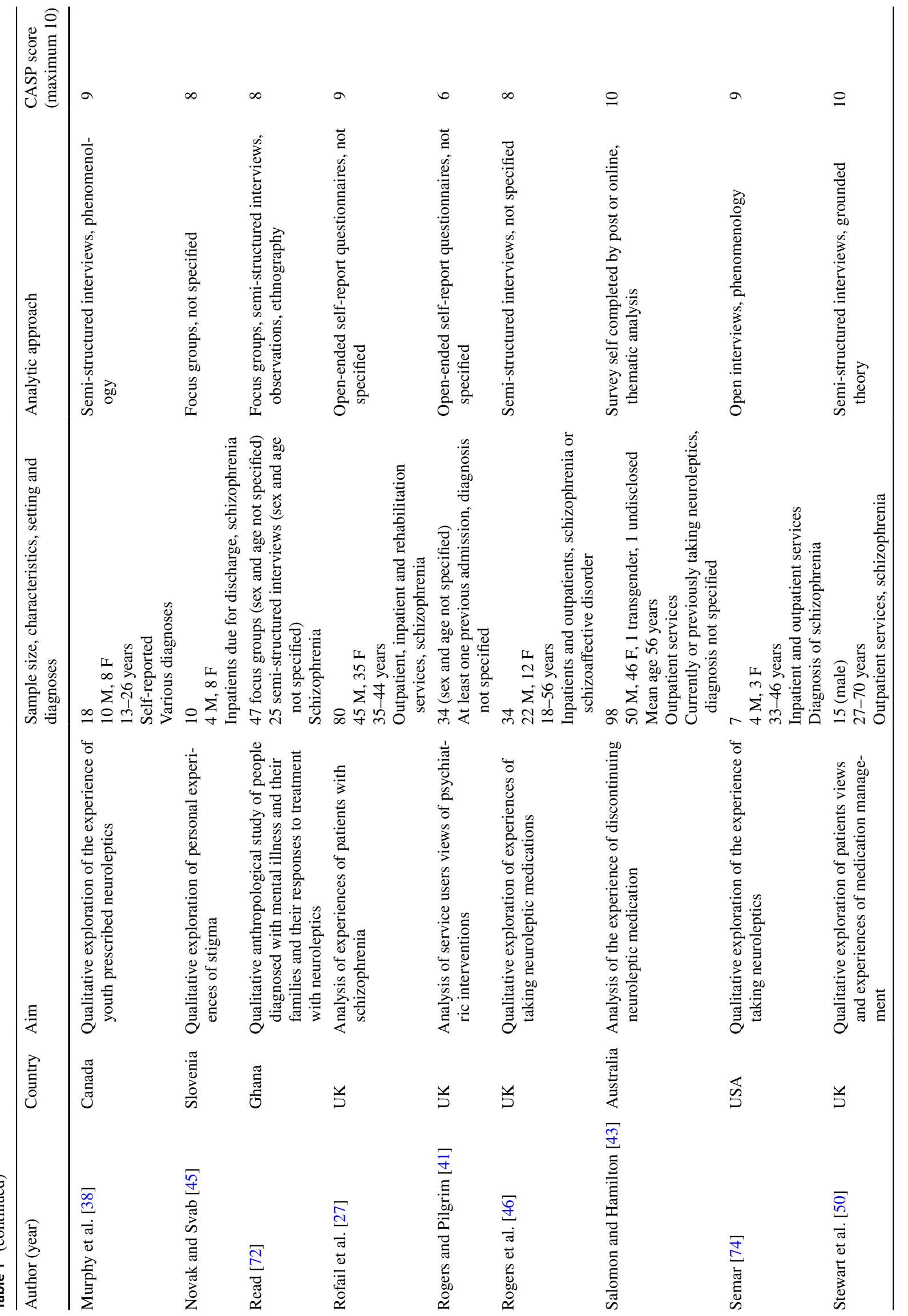




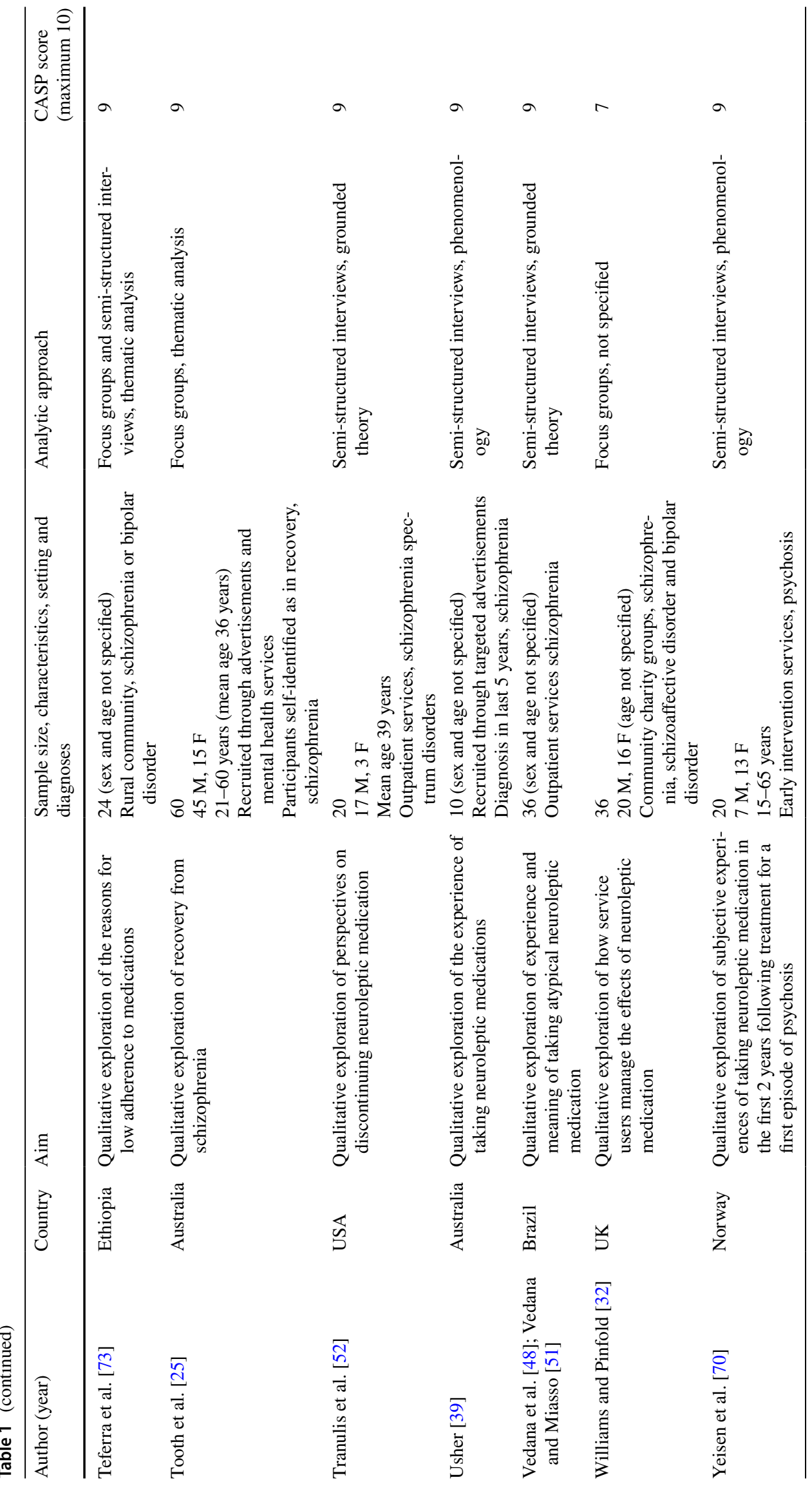


one focused on the experience of taking depot medication exclusively [24]. Others involved people who were taking a variety of agents (see Table 1). Quality scores are shown in Table 1.

\section{Themes (Table 2)}

In the following analysis, we begin with how alterations to normal conscious experience, emotions, cognition and behaviour are described, in line with our first research question. We then explore how the drugs impacted on symptoms of psychosis and other symptoms and problems. Overall, the first theme consists mainly of negative comments about neuroleptic-induced changes that were usually experienced as unpleasant. In comparison, descriptions of effects on symptoms are primarily positive. Themes 3 and 4 address our second research question and focus, respectively, on how neuroleptics affect people's sense of self in both positive and negative ways, and on impacts on agency and how people perceive their level of control over the use of these drugs.

1. Neuroleptic-induced mental and behavioural alterations

'The majority of participants spoke of feeling stupefied, numb and slowed down, of being unable to interact in a normal fashion or undertake even modest activities, most wanting to sleep or lie down' (pg S73) [25].

'I remember taking my first depot... and it absolutely knocked me out... I couldn't even lift a dustpan and brush in that I didn't have any movement in my arms, in my legs... I didn't have any thoughts in my head. I couldn't do anything... I was like a zombie' (pg 117) [26].

Across studies participants provided consistent descriptions of a distinctive state produced by neuroleptics This generally consisted of lethargy, cognitive difficulties, dampened emotions and reduced motivation, which was associated with a variety of physical effects and could lead to impaired functioning. Participants in many studies complained of feeling sedated and fatigued $[4,7,8,18,19,22$, 24-26] and highlighted the strength and unpleasantness of these effects using descriptions such as 'dopey,' [27] 'zonked,' [28] feeling like a 'cabbage' [29] or 'being hit by a truck' [30]. These effects were summarised in one study as 'crippling lethargy' [31]. Associated with this were complaints of impaired cognitive function [23, 29, 31-39], emotional blunting [31, 37, 38] and loss of motivation $[23,26,29,30,32,35-37,40]$, which were again described as profound and debilitating. Across studies, participants referred to feeling they had reduced clarity of thinking, intelligence, concentration and memory and felt 'slowed down' [31]. They referred to feeling 'numbed out,' [31] 'empty' [38], 'lazy' [36], being 'less enthusiastic about life' [35] and lacking 'motivation and energy' [41]. In some studies, these effects were associated with incapacitating physical effects including muscle weakness, stiffness and tremor [23, 26, 28, 32, 33, 41]. Sexual dysfunction, particularly erectile dysfunction and loss of libido $[23,33,34,40]$, and weight gain $[23,27,30,31,33$, 35-37, 40-43] were also common.

The negative impacts of these effects on the ability to function were often considerable [23, 27, 28, 36, 39, 44-46]. They prevented people from having the motivation or physical capability to carry out simple tasks like brushing their teeth [39], using a dustpan and brush [26] or going shopping [34]. Participants in some studies mentioned how the effects of neuroleptics prevented them from working $[27,46]$. In some studies it was noted that the experience of taking neuroleptics had made some people depressed, anxious or suicidal [27, 31, 32, 34, 36, 37]. Participants in ten studies explicitly compared the general state of physical, emotional and cognitive impairment that neuroleptics produced to being a 'zombie' [26, 28, 29, 31, $32,34,37,38,42,46]$.

2. Impact on symptoms

Table 2 Themes

\begin{tabular}{|c|c|c|}
\hline Themes & References & Total \\
\hline 1. Global effects of neuroleptics & {$[23,25-52,69-74]$} & 35 \\
\hline 2. Impact on symptoms & {$[23,26,27,29,33-35,37,39,40,46,47,71,74]$} & 14 \\
\hline $\begin{array}{l}\text { 3. Medication and the self } \\
\text { (a) Depleting the self }\end{array}$ & {$[23,30-33,35-39,41,43,72]$} & 12 \\
\hline (b) Restoring the self & {$[23,26,27,34,39]$} & 5 \\
\hline (c) Symbolic effects & {$[24,28-30,32-35,38,39,44-46,49,51,52]$} & 16 \\
\hline 4. Agency and medication & {$[23-26,28,30-36,38-44,46-52,70,71,74]$} & 29 \\
\hline
\end{tabular}


'I can see a change in my thinking, I used to have some...oh, you know, some funny thoughts... this medication helps me in a way that I can think... and see that it's not right (thinking)...it has offered me hope again for a normal life' (pg 148) [39].

'Others described how the medication decreased the intensity, intrusiveness or emotional impact of psychotic symptoms or unwelcome thoughts' (pg 6) [37].

Despite the nature of drug-induced alterations, many participants across studies felt that neuroleptics had helped to reduce symptoms and, as a consequence, improve their day to day life. Participants in numerous studies reported that the drugs decreased auditory hallucinations or 'voices' [23, 26, $27,33-35,37,46,47]$. In addition, three studies described how some participants felt that the medication improved their clarity of thinking $[27,34,37]$ which was attributed in one study to reduced feelings of mental confusion [34].

Data in some studies provided an insight into how symptom improvement might reflect the global effects induced by neuroleptics described above. In some studies, participants described how the cognitive and emotion blunting effects of neuroleptics interacted with symptoms in a beneficial way, acting as a 'shield' or a 'glove' to minimise the impact of psychotic experiences or beliefs [23, 35]. They described how the medication 'slowed down', 'muffled' or quietened voices $[26,34]$ or reduced symptoms or distress more generally $[35,40]$, as expressed in the idea that the medication 'deadens things down' [40]. A participant in one study described how the drugs helped by producing a 'blockage of brain functions' [23] and others expressed the idea that the medication acted as a protection against the intrusion of unwanted emotions or symptoms, acting as a 'nice buffer between my anxiety/emotions and the outside world' [37] and 'giving my soul some protection' [23].

Although there were more reports of sedative effects being unwelcome and unpleasant, participants in some studies reported that they valued the sedative effects of neuroleptics for their ability to increase sleep [23, 27, 33, 35, 37] and to produce feelings of calmness and relaxation [23, 26, $27,34,37,46]$. These effects were especially evident in the study of clozapine [23]. In a number of studies, participants reported that neuroleptic medication improved the stability of their mood and helped them to become more 'levelheaded' [23, 27, 33, 35, 37].

Data from several studies suggested that the symptom reduction achieved by neuroleptics appeared to improve people's ability to function or 'cope' [46] and enabled some to lead a 'fairly normal life' [23, 27, 29, 34, 39, 46]. The authors of one study concluded that neuroleptics worked 'not by completely removing symptoms, but by calming the self and muffling the voices enough so that life was manageable and the person felt good.' [34].
3. Medication and the self

(a) Depleting the self

'A majority of these participants spoke specifically about the impairment to selfhood associated with psychotropic drug use, such as damaged psychic connections to others and other losses of a spiritual nature' (pg 48) [31].

'It makes me fat, depressed, lethargic. It strips my life and soul' (pg 163) [43].

Across studies, some participants identified how the general alterations produced by neuroleptics affected their sense of self in a negative way, depriving them of valued aspects of their personality. The emotion-dampening effects of neuroleptics, their impact on motivation and initiative and the general dulling of cognitive capacities were particularly perceived as producing unwanted changes [36, 37]. 'Your mind changes and you think differently' was how a participant from one study put it [39]. This made people feel as if they had lost their real selves: 'I felt like a zombie. I did not feel like myself' [38]. In addition, some people mentioned the loss of creativity [32,33,35,37], imagination [41], humour [37] or a sense of 'spirituality and spiritual connection' [31]. They described how this altered their sense of who they were in a negative way, leading to 'an impairment of selfhood,' [31] or a loss of one's 'soul' [43] or 'spiritual nature' [31]. One study concluded that the effects of neuroleptic medication disrupted people's 'emotional and perceptual being-inthe-world,' but also commented on how these effects could be difficult to separate from the individual's 'illness experience' [34]. Drug-induced physical changes like weight gain $[23,30,32,35,43]$ and sexual dysfunction $[34,40]$ were also discussed in terms of how they negatively affected people's sense of themselves and how they understood that they would be perceived by others.

\section{(b) Restoring the self}

On medication 'the person felt in better control of him/ herself and recognised that she/he was functioning more and more like the old self' (pg 135) [34].

'When I started taking medication, I felt like a new man. I was taking [name of antipsychotic] and I was getting on with it, I felt really positive, I felt levelheaded' (Y06) (pg 114) [26].

In contrast, a few participants in some studies identified how improvements in their mental symptoms produced by medication enabled them to regain a sense of self that had been negatively affected by their condition [26, 27, 34, 39]. People described feeling more like their 'old self' [34], a 
'new man' [26], having hope of a 'normal' life and feeling like an 'ordinary' person again [39]. They described how, by enabling them to return to activities they enjoyed that were consistent with their underlying desires and values, neuroleptic medication enhanced their self-esteem [26] and helped them to feel 'worthwhile' [39]. Participants in some studies were reported as feeling that treatment had restored them to 'normal,' [23, 34], although the authors of one paper commented on how it was 'only a few' participants that held this view [23]. However, it seems that for some people neuroleptics facilitated the repair of a previously disrupted sense of self.

\section{(c) Symbolic effects}

'In this way, the act of continuously ingesting the medication makes the individual feel compelled to reaffirm and to acknowledge the schizophrenia. Therefore, due to being strongly linked, the medication can be as undesirable as the schizophrenia' (pg 367) [48].

'I felt it was eroding of my self-image and when I took the medication it was more or less saying that I wasn't whole' (pg 150) [39].

Apart from the direct, pharmacological effects, taking neuroleptic medication also had a symbolic impact on people's sense of identity. For many people, the medication represented the fact that they were a patient with a disease. A few participants welcomed this view [30, 33, 34, 46, 49, 50]. Some others described how they had initially believed the medication represented a 'cure' for their disease, but later became disillusioned with this idea [30, 34, 35, 44], coming to see their previous beliefs in the possibility of a 'miracle cure' [34] as overly simplistic or 'reductionist' [30].

Participants from several studies expressed how they did not want to regard themselves as having 'schizophrenia' or a long-term condition and for these people, taking neuroleptic medication symbolised an unwanted and stigmatised identity as a chronic psychiatric patient $[24,29,33,38,39,44,51$, 52]. They felt that needing to take medication made them 'lesser people' [39] and confirmed to others that they were 'weird' [24], 'mad' [44] or 'crazy' [38], especially because the effects of neuroleptics were sometimes very visible and described as making people 'look ill' [32] or 'like a patient [29]. Neurological effects [28, 32, 39, 42, 45, 46] and weight gain $[23,39,45]$ particularly contributed to this. There was a sense expressed in some studies that being regarded as needing medication denied the participants' own intrinsic value, as if without treatment they were simply seen as the manifestation of a disease process and not a fully fledged person [34, 52]. A participant from one study expressed it as follows:
"They would think that the pill itself is what's helping me be a person. And I mean, that's not the case. Whether I took it or not, I still have value" [52].

\section{Agency and medication}

'Several of the interviewees felt that they had no control over, or ability to influence, their drug treatment. There are many examples in the interviews of situations where the choices of drugs and doses were made by the psychiatrist without prior discussion with the person about former experiences of the drugs or of his or her own preferences' (pg 824) [33].

'I always accepted the medication. It may have made me feel bad, but I accepted it. I accepted it without complaint' (P33) [48].

Many participants across studies appeared to have a passive attitude towards their medication that was often related to a broader sense of loss of agency. In some studies, for example, participants were noted to endure serious and unpleasant adverse effects without complaint, as if this was the normal, expected outcome of treatment [28, 48]. In several studies participants explained that they took medication simply because doctors told them to, and many felt they had no choice over it, nor did they understand what the medication was for or how it was meant to work [30-32, 36, $39,42,47-49,52]$. The authors of one study commented that people who accepted neuroleptic medication were often unable to articulate exactly why they took it [31]. In various studies, participants described feelings of hopelessness, helplessness, fear, confusion or indifference concerning their neuroleptic medication [28, 31, 33, 36, 48-50, 52].

Data from included studies also record how participants perceived their autonomy over medication to be restricted by assumptions about the underlying disorder, often reporting medication taking as necessary to avoiding a further relapse or rehospitalisation $[23,26,30,31,35,36,40,43$, $44,51]$. For some this involved having to "put up with side effects' [42], but they concluded that taking the medication was 'the lesser of two evils' [38]. Others described broader social processes in which medication and reduced autonomy were related. Some were subject to formal legal controls, or felt that there was an informal threat of rehospitalisation if they did not accept medication [26, 31, 36, 42, 46, 49]. Some described pressure from mental health professionals, relatives or friends [26, 31, 36, 39, 46], and some voiced concern about losing access to care and services if they refused medication $[30,46]$. Across studies, participants also described the impediments to taking an active role in decisions about their treatment due to not being given 
information or opportunities to express their preferences [26, 30-33, 36, 38, 39, 42, 43, 46, 47, 49, 52].

These effects combined to produce what some studies termed a 'resigned' or 'reluctant' acceptance of medication $[28,36]$. Some participants had 'given up' trying to exert an influence over their treatment and a state of passive endurance had become a 'pervading way of life' for many people [28]. However, passive acceptance was not ubiquitous: many studies also reported some participants who actively embraced taking neuroleptic medication, and described contributing to decisions about their treatment in the context of a positive and collaborative relationship with their clinicians $[24,26,30,33,34,36,42,43,47-51]$. Others actively resisted the expectations of professionals and asserted their autonomy over their medication either by discontinuing it altogether [26, 30, 31, 34, 42, 43, 46, 48, 51], or by modifying the regime to suit their needs $[26,28,33,36,45,46]$.

\section{Discussion}

The current paper synthesises data from the increasing number of studies of people's experiences of neuroleptic medications. Users of neuroleptics consistently described a distinctive experience characterised by sedation, cognitive impairment, emotional blunting and reduced motivation, which was associated with a variety of physical effects, including neurological effects, weight gain and sexual dysfunction. These effects are also documented in non-clinical samples [53]. They have been referred to in the past as 'neuroleptic-induced deficit' syndrome [54], 'neuroleptic dysphoria' [55] and 'deactivation syndrome' [56], and they have been linked with negative effects on quality of life [55]. Harsher critics suggest neuroleptic effects represent a form of chemical modification of behaviour and personality $[56,57]$. In the current study, the effects of neuroleptics were reported to interfere with people's ability to carry out basic activities, but they were also associated with beneficial effects on the symptoms of psychosis and some other symptoms such as anxiety and insomnia. When medication reduced the intensity of intrusive psychotic experiences and other symptoms, it was able to improve people's ability to function and restore a sense of normality. Others found the mental restriction and physical alterations hard to bear, and experienced a loss of important aspects of their sense of self and agency.

The data therefore provide some support for suggestions that dampening of emotional responses and slowing of cognitive processes may explain the ability of neuroleptic drugs to reduce psychotic symptoms $[8,9,58]$. Some authors have suggested that the therapeutic emotional effects of neuroleptics are mediated through the dopamine system [10], but the fact that neuroleptics have varying effects on many other neurotransmitter systems that affect arousal, cognition and emotion (noradrenaline and serotonin, for example) [59, 60] suggests that the origins of these effects may be more complex.

Anything that changes our mental faculties is likely to impact on our sense of ourselves, and this is a common experience in relation to mood or experience-modifying agents [11]. In the studies we reviewed, some participants felt neuroleptic-induced effects deprived them of important aspects of their personality; their drives, imagination or humour, for example. Others felt that by reducing the symptoms of psychosis, the drugs were able to restore them to a state in which they felt 'themselves' again. Similarly, some people were content to view themselves as having a disease requiring ongoing treatment, while others felt that taking neuroleptic medication symbolised a tainted identity. Schizophrenia or psychosis can disrupt people's sense of self $[61,62]$, and studies of personal recovery have described the importance of reconstructing a sense of self [63] in a way that is distinct from symptom improvement [64]. Therefore, although neuroleptics may effectively suppress symptoms, their effects can nevertheless be experienced as detrimental to sense of self and identity, with important implications for social functioning and achievement of life goals.

Several studies, including some of those included in this review, have commented on the loss of autonomy experienced by people with severe mental disorder, and their relative lack of involvement in decision-making compared to patients with other medical conditions [36, 46, 65]. In the current review, this was due to the ongoing or recurrent nature of the underlying condition, legal restrictions, informal pressures from family, friends or professionals, or lack of encouragement by clinicians to be involved in treatment decisions. The passivity and occasional indifference described in several studies may also reflect the effects of neuroleptics on energy and motivation, or might alternatively be a manifestation of the negative symptoms of schizophrenia in some cases. A previous systematic review also highlighted loss of autonomy in neuroleptic users, identifying this as occurring in relation to early treatment of the acute stages of the condition, and suggesting that people regain a sense of agency as their condition stabilises [13]. In contrast, the current review found that across studies, there appeared to be a group of people who had fallen into a longterm state of passivity and hopelessness in relation to their neuroleptic medication.

\section{Limitations}

The included studies were diverse in their settings and populations studied, but most were conducted in Western countries and studies not published in English were not included. Therefore, findings may not generalise to other parts of the 
world. The quality of the papers was generally high, but studies employed diverse methods of data collection and analysis and the aims and focus of different studies also varied. Given the variety of populations and the consistency of results, the analysis suggests that the included studies provide a reasonably representative view of the typical experience of taking neuroleptic medication.

Qualitative methods of systematic reviewing are still relatively new [20], but thematic synthesis facilitates the analysis of a relatively large number of studies, and allows for a broad summary of the literature. The collaborative nature of the current analysis through the various iterations ensured that the themes were firmly grounded in the data.

\section{Clinical implications}

Clinicians have been found to underestimate the impact of the adverse effects of neuroleptics on patients' quality of life $[66,67]$, which may contribute to the difficulties of achieving a more collaborative approach to decision-making with people with severe mental disorders [65, 68]. A fuller understanding of how neuroleptic drugs impact on important aspects of people's experience and feelings about themselves, and how these effects are entwined with effects on symptoms will enable clinicians to better recognise and respond to patients' concerns. This can facilitate better collaboration and improve clinicians' ability to support patients to retain agency and make informed decisions about their drug treatment based on balancing the benefits of neuroleptic drugs against the unwanted changes they can produce.

Acknowledgements The authors would like to thank the North East London Foundation Trust for providing administrative support for this research

\section{Compliance with ethical standards}

Conflict of interest On behalf of all authors, the corresponding author states that there is no conflict of interest.

Open Access This article is licensed under a Creative Commons Attribution 4.0 International License, which permits use, sharing, adaptation, distribution and reproduction in any medium or format, as long as you give appropriate credit to the original author(s) and the source, provide a link to the Creative Commons licence, and indicate if changes were made. The images or other third party material in this article are included in the article's Creative Commons licence, unless indicated otherwise in a credit line to the material. If material is not included in the article's Creative Commons licence and your intended use is not permitted by statutory regulation or exceeds the permitted use, you will need to obtain permission directly from the copyright holder. To view a copy of this licence, visit http://creativecommons.org/licenses/by/4.0/.

\section{References}

1. Royal College of Psychiatrists (2014) Report of the Second Round of the National Audit of Schizophrenia (NAS). Royal College of Psychiatrists, London

2. Lehman AF, Lieberman JA, Dixon LB, McGlashan TH et al (2004) Practice guideline for the treatment of patients with schizophrenia, second edition. Am J Psychiatry 161(2 Suppl):1-56. https ://doi.org/10.1037/0003-066x.57.12.1052

3. Leucht S, Tardy M, Komossa K et al (2012) Antipsychotic drugs versus placebo for relapse prevention in schizophrenia: a systematic review and meta-analysis. Lancet 379:2063-2071. https://doi. org/10.1016/S0140-6736(12)60239-6

4. Bylerly M, Nakonezny PA, Lescouflair E (2007) Antipsychotic medication adherence in schizophrenia. Psychiatr Clin N Am 30:437-452

5. García S, Martínez-Cengotitabengoa M, López-Zurbano S et al (2016) Adherence to antipsychotic medication in bipolar disorder and schizophrenic patients. J Clin Psychopharmacol 36:355-371. https://doi.org/10.1097/JCP.0000000000000523

6. Murray RM, Quattrone D, Natesan S et al (2016) Should psychiatrists be more cautious about the long-term prophylactic use of antipsychotics. Br J Psychiatry 209:361-365. https://doi. org/10.1192/bjp.bp.116182683

7. Deniker P (1960) Experimental neurological syndromes and the new drug therapies in psychiatry. Compr Psychiatry 1:92-102

8. Moncrieff J (2013) The Bitterest Pills: the troubling story of antipsychotic drugs. Palgrave Macmillan, London

9. Healy D (1989) Neuroleptics and psychic indifference: a review. J R Soc Med 82:615-619. https://doi.org/10.1177/0141076889 08201018

10. Kapur S (2003) Psychosis as a state of aberrant salience: a framework linking biology, phenomenology, and pharmacology in schizophrenia. Am J Psychiatry 160:13-23

11. Stevenson F, Knudsen P (2008) Discourses of agency and the search for the authentic self: the case of mood-modifying medicines. Soc Sci Med 66:170-181. https://doi.org/10.1016/j.socsc imed.2007.07.005

12. Malpass A, Shaw A, Sharp D et al (2009) "Medication career" or "moral career"? The two sides of managing antidepressants: a meta-ethnography of patients' experience of antidepressants. Soc Sci Med 68:154-168

13. Bjornestad J, Lavik KO, Davidson L et al (2019) Antipsychotic treatment-a systematic literature review and metaanalysis of qualitative studies. J Mental Health. https://doi. org/10.1080/09638237.2019.1581352

14. Baumeister RF (1999) The Self in Social Psychology. Psychology Press, Philadelphia, PA

15. Elder GH, Johnson MK, Crosnoe R (2003) The emergence and development of life course theory. In: Mortimer JT, Shanahan MJ (eds) Handbook of the life course. Springer US, Boston, pp 3-19

16. Moher D, Liberati A, Tetzlaff J et al (2009) Preferred reporting items for systematic reviews and meta-analyses: the PRISMA statement (Chinese edition). J Chin Integr Med 7:889-896. https ://doi.org/10.3736/jcim20090918

17. Critical Appraisal Skills Program (2013) CASP, Qualitative research checklist. Dept Gen Pract Univ Glasg 1303:1-6. https:// doi.org/10.1111/j.1600-0447.1980.tb10232.x

18. Hannes K (2011) Critical appraisal of qualitative research. In: Noyes J, Booth A, Hannes K et al. (eds) Supplementary guidance for inclusion of qualitative research in Cochrane systematic reviews of interventions, Version 1, Chapter 4, pp 10-14, Cochrane Collaboration Qualitative Methods Group. http://cqrmg .cochrane.org/supplemental-handbook-guidance 
19. Lachal J, Revah-Levy A, Orri M, Moro MR (2017) Metasynthesis: an original method to synthesize qualitative literature in psychiatry. Front Psychiatry. https://doi.org/10.3389/fpsyt.2017.00269

20. Thomas J, Harden A (2008) Methods for the thematic synthesis of qualitative research in systematic reviews. BMC Med Res Methodol 8:45. https://doi.org/10.1186/1471-2288-8-45

21. Braun V, Clarke V (2006) Using thematic analysis in psychology. Qual Res Psychol 3:77-101

22. Barry CA (1999) Teamwork in qualitative research. Qual Health Res 9:26-44

23. Angermeyer MC, Löffler W, Müller P et al (2001) Patients' and relatives' assessment of clozapine treatment. Psychol Med 31:509-517. https://doi.org/10.1017/S0033291701003749

24. Das AK, Malik A, Haddad PM (2014) A qualitative study of the attitudes of patients in an early intervention service towards antipsychotic long-acting injections. Ther Adv Psychopharmacol 4:179-185. https://doi.org/10.1177/2045125314542098

25. Tooth B, Kalyanasundaram V, Glover H, Momenzadah S (2003) Factors consumers identify as important to recovery from schizophrenia. Australas Psychiatry. https://doi. org/10.1046/j.1440-1665.11.s1.1.x

26. Mills A, Lathlean J, Bressington D et al (2011) Prisoners' experiences of antipsychotic medication: influences on adherence. J Forensic Psychiatry Psychol 22:110-125. https://doi. org/10.1080/14789949.2010.509804

27. Rofail D, Heelis R, Gournay K (2009) Results of a thematic analysis to explore the experiences of patients with schizophrenia taking antipsychotic medication. Clin Ther 31:1488-1496. https:// doi.org/10.1016/j.clinthera.2009.07.001

28. Morrison P, Meehan T, Stomski NJ (2015) Living with antipsychotic medication side-effects: the experience of Australian mental health consumers. Int J Mental Health Nurs 24:253-261. https ://doi.org/10.1111/inm.12110

29. Gill A, Morral P, Knapp P (2016) Living with schizophrenia and atypical medication. Mental Health Practice 19:12-19

30. Geyt GL, Awenat Y, Tai S, Haddock G (2017) Personal accounts of discontinuing neuroleptic medication for psychosis. Qual Health Res 27:559-572. https://doi.org/10.1177/1049732316 634047

31. Hagen BF, Nixon G, Peters T (2010) The greater of two evils? How people with transformative psychotic experiences view psychotropic medications. Ethical Hum Psychol Psychiatry 12:44-59. https://doi.org/10.1891/1559-4343.12.1.44

32. Williams K, Pinfold V (2006) Mental health service users' experiences of the side effects of antipsychotic medication. Rethink Publications, London

33. Bülow P, Andersson G, Denhov A, Topor A (2016) Experience of psychotropic medication-an interview study of persons with psychosis. Issues Mental Health Nurs 37:820-828. https://doi. org/10.1080/01612840.2016.1224283

34. Dumas R (1999) The lived experience of taking neuroleptic medication by persons with schizophrenia. University of Arizona, Unpublished $\mathrm{PhD}$ thesis

35. Gray R, Deane K (2016) What is it like to take antipsychotic medication? A qualitative study of patients with first-episode psychosis. J Psychiatr Mental Health Nurs 23:108-115. https://doi. org/10.1111/jpm. 12288

36. Morant N, Azam K, Johnson S, Moncrieff J (2018) The least worst option: user experiences of antipsychotic medication and lack of involvement in medication decisions in a UK community sample. J Mental Health 27:322-328. https://doi.org/10.1080/09638 237.2017.1370637

37. Moncrieff J, Cohen D, Mason JP (2009) The subjective experience of taking antipsychotic medication: a content analysis of Internet data. Acta Psychiatr Scand 120:102-111. https://doi.org/10.111 1/j.1600-0447.2009.01356.x

38. Murphy AL, Gardner DM, Kisely S et al (2015) A qualitative study of antipsychotic medication experiences of youth. J Can Acad Child Adolesc Psychiatry 24:61-69

39. Usher K (2001) Taking neuroleptic medications as the treatment for schizophrenia: a phenomenological study. Aust $\mathrm{N}$ Z J Ment Health Nurs 10:145-155. https://doi.org/10.104 6/j.1440-0979.2001.00205.x

40. Gee L, Pearce E, Jackson M (2003) Quality of life in schizophrenia: a grounded theory approach. Health Qual Life Outcomes 1:31. https://doi.org/10.1186/1477-7525-1-31

41. Rogers A, Pilgrim D (1993) Service users' views of psychiatric treatments. Sociol Health Illn 15:612-631. https://doi. org/10.1111/1467-9566.ep11433593

42. Carrick R, Mitchell A, Powell RA, Lloyd K (2004) The quest for well-being: a qualitative study of the experience of taking antipsychotic medication. Psychol Psychother 77:19-33. https://doi. org/10.1348/147608304322874236

43. Salomon C, Hamilton B (2013) "All roads lead to medication?" Qualitative responses from an Australian first-person survey of antipsychotic discontinuation. Psychiatr Rehabil J 36:160-165. https://doi.org/10.1037/prj0000001

44. Meshach OE, King KM, Fulton JA (2014) Poor adherence to antipsychotics amongst schizophrenia patients in Nigeria. Int J Cult Mental Health 7:246-258. https://doi.org/10.1080/17542 863.2013.783091

45. Novak L, Svab V (2009) Antipsychotics side effects' influence on stigma of mental illness: focus group study results. Psychiatr Danub 21:99-102

46. Rogers A, Day JC, Williams B et al (1998) The meaning and management of neuroleptic medication: a study of patients with a diagnosis of schizophrenia. Soc Sci Med 47:1313-1323

47. Duxbury JA, Wright KM, Bradley DM, Roach P (2009) A study of the views of patients and nurses about the administration of medication in the acute mental health setting: research in brief. J Psychiatr Mental Health Nurs 16:672-677. https://doi.org/10.11 11/j.1365-2850.2009.01423.x

48. Vedana KGG, Cirineu CT, Zanetti ACG, Miasso AI (2013) Agindo em busca de alívio: enfrentamento da esquizofrenia e dos incômodos ocasionados pelo tratamento medicamentoso. Ciência Cuid Saúde 12:365-374. https://doi.org/10.4025/cienccuidsaude. v12i2.20342

49. Lacasse JR, Hayes Piel M, Lietz CA et al (2016) The client experience of psychiatric medication: a qualitative study. Soc Work Mental Health 14:61-81. https://doi.org/10.1080/15332 985.2015.1058312

50. Stewart DC, Anthony GB, Chesson R (2010) "It's not my job. I'm the patient not the doctor": patient perspectives on medicines management in the treatment of schizophrenia. Patient Educ Couns 78:212-217. https://doi.org/10.1016/j.pec.2009.06.016

51. Vedana KGG, Miasso AI (2014) The meaning of pharmacological treatment for schizophrenic patients. Rev Lat Am Enfermagem 22:670-678. https://doi.org/10.1590/0104-1169.3427.2466

52. Tranulis C, Goff D, Henderson DC, Freudenreich O (2011) Becoming adherent to antipsychotics: a qualitative study of treatment-experienced schizophrenia patients. Psychiatr Serv 62:888-892. https://doi.org/10.1176/ps.62.8.pss6208_0888

53. Healy D, Farquhar G (1998) Immediate effects of droperidol. Hum Psychopharmacol 13:113-120. https://doi.org/10.1002/ (SICI) 1099-1077(19980 3)13:2\%3c113:AID-HUP95 8\%3e3.0.CO;2-N

54. Lader M (1993) Neuroleptic-induced deficit syndrome: old problem, new challenge. J Psychopharmacol 7:392-393 
55. Voruganti L, Awad AG (2004) Neuroleptic dysphoria: towards a new synthesis. Psychopharmacology 171:121-132

56. Breggin $P$ (2008) Brain disabling treatments in psychiatry: drugs, electroshock, and the psychopharmaceutical complex, 2nd edn. Springer Pub, New York

57. Szasz TS (1957) Some observations on the use of tranquilizing drugs. AMA Arch Neurol Psychiatry 77:86-92. https://doi. org/10.1001/archneurpsyc.1957.02330310096016

58. Moncrieff J, Cohen D (2005) Rethinking models of psychotropic drug action. Psychother Psychosom 74:145-153

59. Chamberlain SR, Robbins TW (2013) Noradrenergic modulation of cognition: therapeutic implications. J Psychopharmachol 27:694-718. https://doi.org/10.1177/0269881113480988

60. Meneses A, Liy-salmeron G (2012) Serotonin and emotion, learning and memory. Rev Neurosci 23:543-553. https://doi. org/10.1515/revneuro-2012-0060

61. Sass LA, Parnas J (1998) Schizophrenia, consciousness, and the self. Schizophr Bull 29:427-444

62. Lysaker PH, Lysaker JT (2010) Schizophrenia and alterations in self-experience: a comparison of 6 perspectives. Schizophr Bull 36:331-340. https://doi.org/10.1093/schbul/sbn077

63. Roe D, Davidson L (2005) Self and narrative in schizophrenia: time to author a new story. Med Humanit 31:89-94. https://doi. org/10.1136/jmh.2005.000214

64. Macpherson R, Pesola F, Leamy M et al (2016) The relationship between clinical and recovery dimensions of outcome in mental health. Schizophr Res 175:142-147. https://doi.org/10.1016/j. schres.2015.10.031

65. Morant N, Kaminskiy E, Ramon S (2016) Shared decision making for psychiatric medication management: beyond the micro-social. Health Expect 19:1002-1014. https://doi.org/10.1111/hex.12392

66. Lambert M, Conus P, Eide P et al (2004) Impact of present and past antipsychotic side effects on attitude toward typical antipsychotic treatment and adherence. Eur Psychiatry 19:415-422. https ://doi.org/10.1016/j.eurpsy.2004.06.031
67. Hofer A, Kemmler G, Eder U et al (2004) Quality of life in schizophrenia: the impact of psychopathology, attitude toward medication, and side effects. J Clin Psychiatry 65:932-939

68. Moncrieff J, Azam K, Johnson S et al (2016) Results of a pilot cluster randomised trial of the use of a Medication Review Tool for people taking antipsychotic medication. BMC Psychiatry 16:1-11. https://doi.org/10.1186/s12888-016-0921-7

69. Jenkins J, Strauss E, Carpenter E, Miller D, Floersch J, Sajatovic $M$ (2005) Subjective experience of recovery from schizophrenia-related disorder and atypical antipsychotics. International Jounral of Social Psychiatry 51(3):211-227. https://doi. org/10.1177/0020764005056986

70. Yeisen R, Bjornestad J, Joa I, Johannessen J, Opjordsmoen S (2017) Experiences of antipsychotic use in patients with early psychosis: A two year followup study. BMC Psychiatry 17:299. https://doi.org/10.1186/s12888-017-1425-9

71. Harris K, Brooks H, Lythgoe G, Bee P, Lovell K, Drake R (2017) Exploring service users', carers' and professionals' perspectives and expereinces of current antispychotic prescribing: A qualtative study. Chronic Illness 13(4):275-287. https://doi. org/10.1177/1742395317694223

72. Read U (2012) "I want the one that will heal me completely so that it won't come back again": The limits of antipsychotic medication in rural Ghana. Transculteral Pyschiatry 49(3-4):438-460. https ://doi.org/10.1177/1363461512447070

73. Teferra S, Hanlon C, Beyero T, Jacobsson L, Shibre T (2013) Perpectives on reasons for non-adherence to medication in persons with schizophrenia in Ethiopia: a qualitative study of patients, caregivers and health workers. BMC Psychiatry 13:168-176

74. Semar D (2000) Making my own acquaintance: A phenomenoloigcal study of taking antipsychotic medication for schizophrenia. Unpublished $\mathrm{PhD}$ thesis. University of Conneticut. 